\title{
Leren leren - leren doceren: een cursus didactische professionalisering voor aios
}

\author{
M.D. Ottink, J.O. Busari, G.G.M. Essed
}

\begin{abstract}
Samenvatting
De opleiding van medisch specialisten verandert in hoog tempo naar een model van competentiegericht opleiden. Hierin gaan artsen in opleiding tot specialist (aios) een grotere verantwoordelijkheid dragen voor hun eigen opleiding. Daarnaast kunnen aios ook een belangrijke bijdrage leveren aan de opleiding van collega's en coassistenten. Er is tot op heden echter onvoldoende aandacht geweest voor de didactische professionalisering van de aios: hoe stuurt men effectief het eigen leerproces, haalt men het beste uit de opleider, verwerft men op een adequate wijze de benodigde competenties, en hoe kan men effectief doceren en samenwerken?

Vanuit de In VIVO-kerngroep Zuidoost-Nederland is een tweedaagse cursus didactische professionalisering voor aios ontwikkeld die in deze behoefte voorziet. In dit artikel worden de opzet van deze cursus en de eerste evaluatieresultaten behandeld. (Ottink MD, Busari JO, Essed GGM. Leren leren - leren doceren: een cursus didactische professionalisering voor aios. Tijdschrift voor Medisch Onderwijs 2008;27(5):239-246.)
\end{abstract}

\section{Inleiding}

\section{Competentiegericht opleiden}

De opleiding van medisch specialisten is aan het veranderen. Als gevolg van maatschappelijke ontwikkelingen worden aan de huidige artsen toenemend eisen gesteld ten aanzien van hun functioneren op verschillende gebieden. Het is hierbij van groot belang dat de artsen in opleiding tot specialist (aios) zich alle competenties van de 'medische professional' eigen maken. ${ }^{1}$ Deze competenties zijn beschreven in het inmiddels gereviseerde Canadian Medical Education Directions for Specialists 2005 (CanMEDS)-framework. ${ }^{2}$ Naast het medisch handelen en kennis \& wetenschap betreft dit organisatievermogen, communicatieve vaardigheden, professionaliteit, samenwerken en maatschappelijk handelen.
Daarnaast nemen medische kennis en mogelijkheden hand over hand toe, waarbij men als arts verplicht is voortdurend op de hoogte te blijven van de actuele wetenschappelijke inzichten. In de klassieke meester-gezel verhouding was de leerling hierbij in belangrijke mate afhankelijk van de opleider. Volgens de huidige inzichten is de aios zelf primair verantwoordelijk voor het eigen leerproces, dat immers niet ophoudt bij de inschrijving in het specialistenregister, maar tot het einde van de beroepsuitoefening moet worden voortgezet. Deze veranderingen in de rol van de aios in zijn eigen opleiding worden ook concreet benoemd en uitgewerkt in de nieuwe opleidingsplannen voor de verschillende specialismen. ${ }^{3}$ Diverse gemoderniseerde opleidingsplannen zijn inmiddels opgesteld waaronder dat van de Obstetrie/Gynaecologie (opleidingsplan HOOG: Herziening Opleiding Obstetrie en Gynaecologie) ${ }^{4}$ en de Kinder- 
geneeskunde (opleidingsplan GOED: Generieke Onderwijs- en Evaluatie Doelen). ${ }^{5}$ De grotere verantwoordelijkheid van de aios voor zijn eigen leerproces wordt hierin uitgewerkt. Hij/zij detecteert zijn sterke en zwakke punten, en stuurt hierbij de eigen opleiding, zich toetsend aan de gestelde kaders.

Om deze verantwoordelijkheid voor het eigen leerproces ook daadwerkelijk te kunnen waarmaken zullen aios over grotere didactische inzichten en vaardigheden moeten beschikken dan voorheen. De voor deze verantwoordelijkheid adequaat toegeruste aios beschikt over didactisch inzicht in de processen van het leren leren, het leren afleren en het leren implementeren van nieuwe kennis en vaardigheden, zowel tijdens de opleiding als bij de zelfstandige uitoefening van het medisch specialisme.

\section{Het ontstaan van In VIVO}

De implementatie van de opleidingsplannen, zoals beschreven in de rapporten HOOG en GOED vindt plaats in het kader van het In VIVO-project (Vaart in Innovatie VervolgOpleidingen). ${ }^{6}$ Dit is een pilotproject binnen de Kindergeneeskunde en Obstetrie/Gynaecologie, geïnitieerd door het CBOG (College voor de Beroepen en Opleiding in de Gezondheidszorg) en het ministerie van Volksgezondheid, Welzijn en Sport, waarbij de implementatie van deze opleidingsplannen gefaciliteerd en geëvalueerd wordt. Lokaal wordt de invoering van de opleidingsplannen begeleid door kerngroepen in de betreffende onderwijs- en opleidingsregio (OOR). Aan de hand van de hierbij opgedane ervaring en de theoretische onderbouwing door aan het project verbonden onderwijskundigen, worden opleidingsrichtlijnen samengesteld, die gebruikt kunnen worden bij de uitwerking en invoering van opleidingsplannen voor andere specialismen.

\section{Didactische professionalisering}

De didactische professionalisering van opleiders wordt breed gezien als een belangrijke voorwaarde om de kwaliteit van de opleiding van medisch specialisten te waarborgen. In de medische vervolgopleiding zijn drie belangrijke elementen aanwezig: de opleider, de opleidingsomgeving en de aios. Samen bepalen deze de kwaliteit en inhoud van de opleiding van de aios. Vooralsnog wordt in de onderwijsontwikkeling en -vernieuwing voornamelijk aandacht besteed aan de eerste twee elementen. Dit gebeurt onder andere in het kader van MSRC-visitaties (Medisch Specialisten Registratie Commissie), door aios-werktijdenbesluiten en 'teach-the-teacher-to-teach'-cursussen. De rol van de aios zelf als (mede)verantwoordelijke voor zijn opleiding en leerproces is hierbij onderbelicht gebleven.

Niet alleen de opleider dient didactisch gekwalificeerd te zijn, ook de aios moet zich op didactisch gebied bekwamen om zijn eigen competentieontwikkeling te sturen en te onderhouden: teach-the-learnerto-learn! ${ }^{1}$ De medische vervolgopleiding is een vorm van zogenaamd 'werkplekleren'. ${ }^{7}$ Het vereist specifieke vaardigheden om optimaal gebruik te kunnen maken van de leermomenten op de werkplek. ${ }^{8}$ Actief creëren van voldoende leermomenten, omgaan met feedback en deze op de juiste wijze gebruiken is noodzakelijk om zich optimaal te kunnen ontwikkelen tot medisch specialist.

Daarnaast speelt de aios ook een belangrijke rol in de competentieontwikkeling van collega's, coassistenten, geneeskundestudenten en verpleegkundigen. Aios moeten hiertoe op efficiënte wijze kennis kunnen overdragen. ${ }^{9-11}$ Minimale vereisten hiervoor zijn inzicht in leerprocessen, het kunnen geven van effectieve feedback en het kunnen evalueren en bijsturen van een leerprogramma en leertraject. 
Andere initiatieven met betrekking tot didactische professionalisering

Ook in andere opleidingsregio's is men doordrongen van de noodzaak voor verdere instructie en training van aios. Zo ontstaan diverse initiatieven voor didactische professionalisering van staf en aios. ${ }^{12-13}$ Ook in specialismen buiten het In VIVO-project zijn dergelijke trajecten gestart.

Bij de implementatie van de onderwijsplannen door het In VIVO-kernteam OOR Zuidoost- Nederland kwamen er bij de opleiding van aios ten aanzien van de bovengenoemde competenties tekortkomingen aan het licht. De In VIVO- projectgroep van de OOR Zuidoost-Nederland heeft daarom het initiatief genomen voor de ontwikkeling van een tweedaagse cursus om in deze leemte te voorzien. De opzet van deze cursus, eerste ervaringen en evaluatie worden in dit artikel besproken.

\section{Ontwikkeling van de cursus}

\section{Behoefteraming}

Binnen de kerngroep In VIVO van de OOR Zuidoost-Nederland werd een werkgroep docentprofessionalisering gevormd. Deze bestond uit drie medisch specialisten (een kinderarts, een kinderarts/medisch onderwijskundige en een gynaecoloog/hoogleraar klinisch onderwijs) en twee aios.

Aan de hand van de literatuur over medisch onderwijs, groepsinterviews en de behoefteramingen met betrekking tot de didactische vaardigheden van aios ${ }^{14-16}$, expert opinion en leertheoretische modellen, werd een overzicht gemaakt van onderwerpen die in een dergelijke cursus zouden moeten worden behandeld. Daarnaast gaven de aios de leden van de werkgroep belangrijke input ten aanzien van de benodigde instructie voor aios over de vernieuwde opleidingsinstrumenten, zoals de ontwikkeling van het portfolio en klinische toetsingsmethodes.

\section{Doel van de cursus}

Het doel van de cursus is de aios te instrueren hoe om te gaan met nieuwe ontwikkelingen, verwachtingen en verantwoordelijkheden in de medische vervolgopleiding. Het gaat hierbij om vier verschillende onderdelen:

- Medische professionaliteit: Het belichten van het profiel van de aios en het belang van hun rol in het leerproces.

- Leren en doceren: Aios bekend maken met leertheorieën, soorten kennis en het proces van kennisverwerving en -overdracht. Aios inzicht bieden in basale onderwijsvaardigheden, die het leren en doceren verbeteren, en aios demonstreren hoe zij deze vaardigheden kunnen gebruiken en hoe deze vaardigheden het leerproces (kunnen) vergemakkelijken.

- Portfolio: Aios inzicht geven in de plaats en het belang van portfolio's in hun professionele opleiding, zodat zij met behulp van het portfolio hun competenties en ontwikkeling effectief kunnen evalueren.

- Beoordelingen: Aios inzicht bieden in de verschillende aspecten van klinische beoordelingen en hen leren hoe deze gebruikt kunnen worden om hun leerproces te evalueren en te verbeteren.

\section{Opzet van de cursus}

Naar aanleiding van de behoefteraming en gestelde doelen werd een cursus ontwikkeld voor aios van alle disciplines. Aangezien de cursus is ontwikkeld in het kader van het In VIVO-project, werd deze het eerst aangeboden aan de aios Kindergeneeskunde en Obstetrie/Gynaecologie van het cluster Zuidoost-Nederland. De cursus heeft een tijdsbestek van twee 
dagen die binnen één week worden gepland en wordt in eerste opzet verzorgd door de werkgroepleden (medisch specialisten, medisch onderwijskundige en aios). De trainingsmethode varieert per sessie, er wordt ondermeer gebruik gemaakt van korte inleidingen, video-illustraties, rollenspelen en groepsdiscussies.
Tevens is er een syllabus ontwikkeld die de hoofdlijnen van de cursus bevat, evenals enkele achtergrondartikelen die de deelnemers als voorbereiding kunnen lezen. De inhoud van de negen sessies van de workshop is weergegeven in tabel 1 .

Tabel 1. Opbouw van de cursus Leren Leren - Leren Doceren.

\begin{tabular}{|c|c|c|}
\hline Sessie & Duur & Inhoud \\
\hline Effectief leren in klinische praktijk & $60 \mathrm{~min}$ & $\begin{array}{l}\text { Er wordt een overzicht geboden van leertheorieën, leerstijlen en } \\
\text { factoren die een rol spelen bij leerprocessen. Ook wordt inge- } \\
\text { gaan op de werking van het geheugen bij het verwerken van } \\
\text { nieuwe informatie en integratie met bestaande kennis. }\end{array}$ \\
\hline Portfolio & $75 \mathrm{~min}$ & $\begin{array}{l}\text { Het doel en belang van een portfolio wordt behandeld. Er wor- } \\
\text { den praktische richtlijnen gegeven over het opbouwen van een } \\
\text { portfolio. Ook het maken van een zelfreflectieverslag en per- } \\
\text { soonlijk opleidingsplan komt aan bod. }\end{array}$ \\
\hline Klinische beoordelingsmethodes & $90 \mathrm{~min}$ & $\begin{array}{l}\text { Verschillende evaluatiemethodieken zoals KPB (korte praktijk } \\
\text { beoordelingen), } 360 \text { graden feedback en OSATS (Objective } \\
\text { Structured Assessment of Technical Skills) worden behandeld. }\end{array}$ \\
\hline Zelfkennis en leerbekwaamheid & $60 \mathrm{~min}$ & $\begin{array}{l}\text { Dit onderdeel is gericht op het verbeteren van de leerbekwaam- } \\
\text { heid van de aios, analyse van hun leerprofiel en het identificeren } \\
\text { van factoren die hierop van invloed zijn. }\end{array}$ \\
\hline Effectief doceren & $60 \mathrm{~min}$ & $\begin{array}{l}\text { Enkele basale aspecten van leren en doceren worden behandeld, } \\
\text { gericht op een optimale instructie of kennisoverdracht. }\end{array}$ \\
\hline $\begin{array}{l}\text { Benutten van aanwezige kennis bij het } \\
\text { aanleren van klinische vaardigheden }\end{array}$ & $60 \mathrm{~min}$ & $\begin{array}{l}\text { Geleerd wordt hoe het gebruiken en reactiveren van eerder op- } \\
\text { gedane kennis het aanleren van complexe materie of vaardighe- } \\
\text { den faciliteert. }\end{array}$ \\
\hline Feedback & $90 \mathrm{~min}$ & $\begin{array}{l}\text { De basisregels voor het geven van goede feedback worden be- } \\
\text { handeld. Geleerd wordt hoe de eigen feedback efficiënt te orga- } \\
\text { niseren. }\end{array}$ \\
\hline Troubleshooting & $75 \mathrm{~min}$ & $\begin{array}{l}\text { Deze sessie is gericht op het onderkennen van problemen in de } \\
\text { opleidingspraktijk. Geleerd wordt hoe met verschillende pro- } \\
\text { bleemsituaties in het onderwijs kan worden omgegaan. }\end{array}$ \\
\hline Time management & $75 \mathrm{~min}$ & $\begin{array}{l}\text { Vaak beschouwt als de } 8^{\mathrm{e}} \text { competentie. In deze sessie worden } \\
\text { handvatten geboden om efficiënt te werken en prioriteiten te } \\
\text { stellen. Geleerd wordt hoe men bij een hoge werkdruk toch tijd } \\
\text { kan vrijmaken voor niet-patiënt gebonden verantwoordelijkhe- } \\
\text { den als onderwijs of onderzoek. }\end{array}$ \\
\hline
\end{tabular}




\section{Ondersteuning door onderwijsinstituut UM}

Tijdens de ontwikkeling van de cursus is samenwerking gezocht met medewerkers van het onderwijsinstituut van de Universiteit Maastricht. Vanuit het onderwijsinstituut is financiële ondersteuning geboden en zal de cursus in de toekomst verder worden gefaciliteerd.

\section{Evaluatie}

De cursus heeft inmiddels twee keer plaatsgevonden voor in totaal 18 aios. De cursus wordt na afloop uitvoerig geëvalueerd. Onderdeel hiervan is een anonieme schriftelijke evaluatie, opgebouwd uit merendeels gesloten vragen en antwoorden, weergegeven aan de hand van een vijfpunts-Likertschaal $(1=$ geheel oneens, $5=$ geheel eens). De deelnemers zijn in principe evenredig verdeeld, zowel over de specialismen Obstetrie/Gynaecologie en Kindergeneeskunde als over de verschillende opleidingsjaren.

Bij de beoordeling van de evaluatieresultaten van de cursussen tot nu toe kwam het volgende naar voren. De opzet van de cursus werd als zeer goed beoor- deeld (4.6), waarbij er voldoende ruimte was voor persoonlijke inbreng (4.4) en ruimte voor discussie (4.9). Alle deelnemers waren van mening dat de cursus hun opleiding ten goede zou komen (4.9). Niet alle deelnemers hadden van tevoren de verspreide syllabus met relevante literatuur doorgenomen (3.4); qua relevantie beoordeelde men de voorbereidende artikelen als neutraal (3.7). Voor de individuele beoordeling van de diverse modules zie tabel 2.

De deelnemende aios vonden de cursus zeer leerzaam. Vooral de praktische toepasbaarheid in de dagelijkse praktijk werd hoog gewaardeerd. Aios werden zich door de cursus bewust van hun rol als leerling en leraar, en van hun (mede) verantwoordelijkheid voor hun eigen opleiding. Ook kregen zij inzicht in de benodigde competenties om adequaat invulling te kunnen geven aan deze verantwoordelijkheid. De aios beschreven de cursus als zeer motiverend en inspirerend. $\mathrm{Zij}$ zagen deze unaniem als een zeer bruikbare cursus die zeker algemeen ingevoerd moet gaan worden.

Tabel 2. Evaluatieresultaten.

\begin{tabular}{lccc}
\hline $\begin{array}{l}\text { Evaluatie cursus Leren Leren - Leren Doceren } \\
\text { (5-punts Likertschaal, 0 = zeer oneens, 5 = zeer eens) }\end{array}$ & $\begin{array}{c}\text { Cursus 1 } \\
\mathrm{n}=8\end{array}$ & $\begin{array}{c}\text { Cursus 2 } \\
\mathrm{n}=10\end{array}$ & $\begin{array}{c}\text { Gewogen gemiddelde } \\
\mathrm{n}=\mathbf{1 8}\end{array}$ \\
\hline & & 4.7 & $\mathbf{4 . 5}$ \\
Introductie & 4.3 & 4.4 & 4.4 \\
Effectief leren in de klinische praktijk & 4.6 & 4.4 & 4.2 \\
Portfolio & 4.5 & 4.1 & 4.2 \\
Klinische beoordelingsmethodes & 4.3 & 4.1 & 4.3 \\
Zelfkennis en leerbekwaamheid & 4.4 & 4.2 & 3.9 \\
Effectief doceren & 4.5 & 3.7 & 4.8 \\
Benutten van aanwezige kennis & 4.2 & 4.6 & 4.4 \\
Feedback & 5.0 & 4.0 & 4.4 \\
Troubleshooting & 4.8 & 4.3 & 4.3 \\
Time management & 4.5 & & \\
\hline Gemiddelde score & & & \\
\hline
\end{tabular}




\section{Discussie}

De cursus 'leren leren - leren doceren' is ontwikkeld door enthousiaste opleiders en aios die deel uitmaken van het kernteam In VIVO OOR Zuidoost-Nederland. De cursus is ontstaan vanuit de gebleken noodzaak tot scholing en ontwikkeling van de aios ten aanzien van hun didactische competenties. In de cursus komen verschillende onderdelen als leren, doceren, feedback, portfolio's en timemanagement aan de orde. Zo worden de aios toegerust met de didactische competenties die het mogelijk maken de verantwoordelijkheid voor de eigen opleiding ook daadwerkelijk zelf te kunnen dragen.

Zoals al eerder vermeld is, bestaan er meerdere initiatieven gericht op de didactische professionalisering van aios. Deze cursus onderscheidt zich ten opzichte van andere initiatieven doordat de methodologie gebaseerd is op evidence in de literatuur en op eerder opgedane ervaringen. ${ }^{14-16} \mathrm{Op}$ basis van een behoefteraming is een systematische cursus ontworpen. De cursus is samengesteld uit theoretische en praktische onderdelen met een afwisseling van theoretische achtergronden, rollenspelen, videofragmenten en groepsdiscussies. Waar veel andere cursussen in didactische professionalisering zich voornamelijk richten op het doceren, is deze cursus vanaf de eerste opzet gericht op het 'leren leren' van aios. Door kennis te nemen van leertheoretische achtergronden krijgen aios meer inzicht in de onderliggende mechanismes van kennisverwerving en -overdracht. Zo kan men het eigen leren bevorderen, inzicht ontwikkelen in de wijze waarop kennis wordt overgedragen en ervaren hoe door inbreng van nieuwe kennis de bestaande kennis wordt geherstructureerd.

Een bijzonder aspect van de cursus is ook de participatie van de aios in de werkgroep. Zij zijn intensief betrokken geweest bij de totstandkoming van de cursus. Zij bewaakten de aansprekende en praktisch bruikbare opbouw van de cursus. Door hun inbreng zijn knelpunten die zich voordoen bij de implementatie van de gemoderniseerde opleidingsplannen, specifieke aandachtspunten in de cursus geworden. Voorbeelden hiervan zijn een sessie over de praktische uitvoering van klinische beoordelingsmethodes als de 360 graden feedback en een sessie over het portfolio leren. Hierin wordt aan de hand van een stappenplan verder ingegaan op het optimaal starten met een portfolio en het op efficiënte wijze verder ontwikkelen tot een instrument voor het documenteren en sturen van de eigen ontwikkeling. Het feit dat de cursus werd ontworpen en geleid door twee opleiders, een onderwijskundige en twee aios gaf een afwisseling qua gezichtspunten, die de cursus ten goede kwam. De eerste ervaringen van de implementatie van deze cursus zijn veelbelovend. Enkele aspecten verdienen nadere bespreking.

De opzet van de cursus vereist een zeer gemotiveerd team van trainers dat met enthousiasme de materie kan overbrengen. Hiertoe wordt een beroep gedaan op een aantal aios en specialisten die, naast hun klinische werkzaamheden, als trainer deelnemen aan dergelijke cursussen, uiteraard na zelf hiervoor gekwalificeerd te zijn. Voldoende competente trainers zijn van belang voor de continuïteit van de cursus. Dit is deze reden dat samenwerking is gezocht met het opleidingsinstituut van de Universiteit Maastricht voor zowel materiële ondersteuning als het leveren van expertise, zodat ook op langere termijn de cursus kan worden gecontinueerd.

Een ander aandachtspunt blijkt de tijdsinvestering van de aios. Cursorisch onderwijs in niet-medisch-technische aspecten wordt door opleiders soms nog als beperkt relevant beschouwd. De loyale me- 
dewerking van opleiders om alle aios in de gelegenheid te stellen een dergelijke cursus te volgen is dan ook van groot belang. In de toekomst, nadat alle zittende aios de cursus hebben gevolgd, betreft het overigens alleen nog beginnende aios.

Tijdens de ontwikkeling van de cursus is er een raming van de kosten gemaakt, mede gebaseerd op ervaringen van andere docentprofessionaliseringscursussen voor opleiders (Basic Clinical Teaching). De kosten bestaan uit huur van de ruimte, huur van audiovisuele apparatuur, lunchkosten, kosten voor syllabi en vergoeding voor de trainers. De kosten worden per cursus begroot op $€ 3500$ euro bij deelname van tien deelnemers.

Wij menen met de cursus 'leren leren leren doceren' voor de aios een bruikbare en praktische tweedaagse cursus te hebben ontwikkeld. De positieve feedback en evaluatieresultaten sterken ons in deze opvatting. Cruciaal is de prominente rol die aios hebben gespeeld in de totstandkoming van de modulen van de cursus, een product van een goede samenwerking tussen opleiders en aios. De cursus zal in het komende jaar vaker worden aangeboden en verder worden ontwikkeld. Alle aios Kindergeneeskunde en Obstetrie/Gynaecologie van de OOR Zuidoost-Nederland zullen de cursus volgen. Naar onze mening is deze cursus tevens geschikt voor aios uit andere klinische disciplines.

\section{Quotes}

'Ik heb in deze cursus aansprekende en zinvolle presentaties gezien over leren, leerstijlen, doceren en evalueren. Termen die zo nogal droog kunnen klinken, maar op een leuke manier werden gebracht, met veel ruimte voor interactie. De groepsgrootte was hierbij goed om open ervaringen te delen en interactief te kunnen zijn. Doordat mede hierdoor de presentaties gepaard gin- gen met veel praktijkvoorbeelden, werd de invulling van de cursus direct heel praktisch. Al met al ben ik weggegaan met veel enthousiasme om het eigen leerproces bewuster vorm te geven en handvatten om coassistenten en semi-artsen beter te kunnen onderwijzen en begeleiden.'

'Ik vond de cursus erg inspirerend. Ik heb vooral veel gehad aan de uitleg over de meerwaarde van een portfolio en een POP (persoonlijk ontwikkelingsplan). Tot nu toe zag ik dit alleen als een noodzakelijk kwaad en niet als een tool om mijn eigen leerpad te verbeteren. Ik denk dat het een zeer goede aanvulling is op de opleiding en ik zal ook zeker mijn collega's adviseren de cursus te gaan volgen.'

'Het is een zeer praktische cursus, waarbij de problematiek rondom 'creëer je eigen leermoment' als uitgangspunten voor de cursus geldt. Hierdoor krijg je veel handvatten aangeboden om je een betere 'leerling' te maken en je opleider een betere 'leraar'. Het is een verhelderende cursus. Naast optimaal leren leren, word je ook gedoceerd in doceren. Van omgaan met ongemotiveerde en arrogante coassistenten, tot feedback geven en jezelf herkennen als student met bijbehorende valkuilen.'

\section{Leden werkgroep Docent- professionalisering In VIVO OOR Zuidoost-Nederland}

Prof. Dr. G.G.M. Essed (Gynaecoloog/ Opleider en Hoogleraar klinische onderwijs). Dr. J.O. Busari (Kinderarts/Medisch onderwijskundige).

Dr. A.L.M. Mulder (Kinderarts/plv. opleider).

Drs. M.D. Ottink (aios, Kindergeneeskunde).

Drs. F.A. Ten Cate (aios, Obstetrie/Gynaecologie). 


\section{Literatuur}

1. Jones R. et al. Changing face of medical curricula. Lancet 2001;357(9257):699-703.

2. Canmeds: http://rcpsc.medical.org/canmeds/ bestpractices/framework_e.pdf .

3 Scheele $\mathrm{F}$ et al. Introducing competency-based postgraduate medical education in the Netherlands. Med Teach 2008;30(3): 248-53.

4. HOOG:

http://www.medischevervolgopleidingen.nl// content/documenten/specialisme/gynaecologie/nvog hoog.pdf

5. GOED:

http://www.medischevervolgopleidingen.nl// content/documenten/invivo/nvk\%20goed $\% 20$ boe kje\%20definitief.pdf

6. In VIVO

http://www.medischevervolgopleidingen.nl// content/ documenten/invivo/1.pdf

7. Teunissen PW et al. Attending doctors' perspectives on how residents learn. Med Educ 2007;41(11):1050-58.

8. Govaerts MJ. In-training assessment: learning from practice. The Clinical Teacher 2006; 3:242 47.

9 Morrison EH, Hafler JP. Yesterday a learner today a teacher too: residents as teachers in 2000 . Pediatrics 2000;105(1 Pt 3): 238-41.

10. Morrison EH et al. The effect of a 13-hour curriculum to improve residents' teaching skills: a randomized trial. Ann Intern Med 2004;141(4):257 63

11. Busari JO, Scherpbier AJ. Why residents should teach: a literature review. J Postgrad Med 2004;50(3):205-10

12. In Vivo docentprofessionalisering: www medischevervolgopleidingen.nl/pages/content/ S2/invivo3.aspx
13. Borleffs $\mathbf{J}$ et al. Les in onderwijzen. Medisch Contact 2003(58):1167-69.

14. Norman GR, Shannon SI, Marrin ML. The need for needs assessment in continuing medical education. BMJ 2004; 328(7446):999-1001.

15. Ratnaplan S and Hilliard R. Needs Assessment in Postgraduate Medical Education: a Review. Medical Education Online [serial online], 2002; 7(8)

16. Busari JO et al. A two-day teacher-training programme for medical residents: investigating the impact on teaching ability. Adv Health Sci Educ Theory Pract 2006;11(2):133-44.

De auteurs:

Drs. M.D. Ottink, aios kindergeneeskunde MUMC+, lid In VIVO-kernteam OOR Zuidoost-Nederland.

Dr. J.O. Busari, kinderarts Atrium MC Heerlen, medisch onderwijskundige, voorzitter In VIVO-kernteam OOR Zuidoost-Nederland, ontwerpleider kindergeneeskunde Landelijke Projectgroep In VIVO.

Prof. dr. G.G.M. Essed, gynaecoloog-perinatoloog, opleider obstetrie/gynaecologie MUMC+, hoogleraar Methodiek Klinisch Onderwijs, lid In VIVO-kernteam OOR Zuidoost-Nederland.

Correspondentieadres:

M.D. Ottink, Vakgroep Kindergeneeskunde, Maastricht Universitair Medisch Centrum, postbus 5800, $6202 \mathrm{AZ}$ Maastricht. Tel. 043-387 7264; e-mail: ottink@gmail.com

Belangenconflict: geen gemeld

Financiële ondersteuning: deze werd geboden door het onderwijsinstituut van de faculteit Health, Medicine and Life Sciences, Universiteit Maastricht

\section{Summary}

The postgraduate medical training is rapidly changing towards a model of competency-based training. This implies that residents have to take responsibility for their own professional training. In addition, medical residents fulfil an important role as teachers of fellow residents and medical students. To date, insufficient attention has been paid to the development of didactic skills in residents necessary for improving their own learning, acquiring the needed competences, and being able to effectively teach and collaborate with others.

The local steering committee on the implementation of the revised curriculum of Obstetrics \& Gynaecology and Paediatrics (In VIVO group) in Southeast Netherlands designed a two-day workshop for residents to address these needs. This article describes the design of the course and first evaluation results after its implementation. (Ottink MD, Busari JO, Essed GGM. Learn to learn, learn to teach: a course on didactic skills for residents. Dutch Journal of Medical Education 2008;27(5):239-246.) 